\title{
Pengaruh Pemberian Berbagai Konsentrasi Indole-3-Butyric Acid (IBA) dan Lama Perendaman terhadap Pertumbuhan Stek Batang Timi (Thymus vulgaris L.)
}

\section{The Effect of Giving Various Concentrations of Indole-3-Butyric Acid (IBA) and Soaking Time on the Growth of Thyme Cuttings (Thymus vulgaris L.)}

\author{
Khodijah Wafia*, Karno, Florentina Kusmiyati \\ Department of Agroecotechnology, Faculty of Animal and Agricultural Science, Diponegoro University, Semarang, Indonesia \\ *Corresponding author. khodijahwafiya@gmail.com
}

Received: October 11, 2020; Accepted: November 27, 2020; Published: April 1, 2021

\begin{abstract}
The method of thyme stem cutting needs to be developed to produce better roots to support growth. The study aims to examine the response of thyme stem cuttings to various concentration of IBA and time soaking. The research was carried out on January - March 2020 in screen house PT. INDMIRA, Sleman, Yogyakarta and the Physiology and Plant Breeding Laboratory of the Faculty of Animal and Agricultural Science, Diponegoro University. The method used was a completely randomized design with a factorial $4 \times 3$ with 5 replications. The first factor was a various concentration of IBA: A0 (0 ppm), A1 (100 ppm), A2 (250 ppm), and A3 (500 ppm). The second factor was the time soaking: B1 (5 minutes), B2 (10 minutes), and B3 (15 minutes.) The results showed that IBA concentration has no significant effect for root dry weight, while the time soaking has significant effect for all parameters. Soaking thyme stem cuttings at an IBA $250 \mathrm{ppm}$ for 10 minutes gave the best results on plant length, the number of leaves, root length, and root dry weight, but soaking in water (without IBA) for 5 minutes was able to give the best number of percentage of life cuttings (85\%) so that giving IBA had no needed.
\end{abstract}

Key words: aromatic herb; auxin synthesis; rooting hormone

Cite this as: Wafia, K., Karno, \& Kusmiyati, F. (2021). Pengaruh pemberian berbagai konsentrasi indole-3butyric acid (IBA) dan lama perendaman terhadap pertumbuhan stek batang timi (Thymus vulgaris L.). Agrosains : Jurnal Penelitian Agronomi, 23(1), 19-26. DOI: http://dx.doi.org/10.20961/agsjpa.v23i1.44802

\section{PENDAHULUAN}

Timi (Thymus vulgaris L.) merupakan tanaman herba aromatik yang memiliki pemanfaatan luas di bidang kesehatan, industri herbal, kosmetik, dan kuliner. Tanaman yang termasuk famili Lamiaceae ini berasal dari daerah Mediterania, yaitu Eropa Selatan, Afrika Utara, hingga Asia Barat (Elhaak \& Gad, 2015). Timi memiliki sekitar 220 genus dan 4000 spesies yang tersebar di seluruh dunia dengan senyawa aktif yang terkandung di dalamnya yaitu thymol, carvacrol, linalool, apigenin, dan eugenol (Javed et al., 2013). Thymol sebagai senyawa aktif utama timi berperan sebagai antimikroba, antiseptik, anti-karsinogenetik, antiinflamasi, serta berpotensi mengobati gangguan pernapasan, mengurangi risiko penyakit kardiovaskular, dan mengatasi reaksi alergi (Salehi et al., 2018). Timi umum dikenal mampu meredakan batuk dan sakit tenggorokan, namun dapat pula digunakan untuk mengobati bronchitis, flu, asma, dan infeksi saluran pernapasan atas lainnya. Selain itu, berpotensi sebagai obat diabetes dan penyakit komplikasi terkait lainnya karena memiliki efek anti-hiperglikemik dan antilipidemik, sedangkan pada industri makanan dan kosmetik, minyak essensial timi dapat digunakan sebagai bahan pengawet dan antioksidan (Dauqan \& Abdullah, 2017). Manfaatnya yang sangat luas tersebut menjadikan tanaman ini penting untuk diperbanyak dan dikembangkan. Budidaya timi yang diteliti di KP Manopo, Lembang, Jawa Barat (1200 m dpl) mampu memproduksi herba mencapai 3,93 ton/ha dan kadar thymol tertinggi $70,90 \%$ (Rahardjo et al., 2020).

Tanaman timi (Thymus vulgaris L.) berupa herba semak dengan morfologi batang lunak hingga berkayu, daun berwarna hijau berukuran kecil dan beraroma khas, bunga berwarna putih keunguan, serta biji bulat berwarna hitam (Delcheh et al., 2014). Tipe perakaran timi berupa akar serabut yang sangat halus berwarna transparan hingga coklat muda. Timi memiliki batang muda yang lunak (soft wood) berwarna hijau dan berkayu apabila sudah tua. Batang muda timi merupakan bagian yang digunakan dalam perbanyakan vegetatif karena persentase keberhasilannya yang lebih tinggi dibandingkan dengan batang tua. Bagian terpenting dari timi yang digunakan sebagai bahan baku industri obat dan kosmetik adalah daun dan batang karena kedua bagian tersebut merupakan bahan ekstraksi minyak atsiri timi (Juárez-Rosete et al., 2014). Perbanyakan tanaman dengan stek batang merupakan salah satu teknik perbanyakan vegetatif dengan memanfaatkan organ batang sebagai bahan perbanyakan stek. Keberhasilan stek batang dipengaruhi oleh kualitas bahan stek batang yang 
digunakan, umur tanaman induk, dan pemberian hormon eksogen yang berhubungan dengan keseimbangan auksin endogen dan kadar karbohidrat pada bahan tanam (Amri et al., (2010). Pertumbuhan stek batang timi dapat ditingkatkan dengan pemberian auksin eksogen yang berfungsi sebagai zat perangsang tumbuh sintetik, salah satunya yaitu Indole-3-Butyric Acid (IBA). IBA dipilih karena sifatnya yang serupa dengan auksin yang dihasilkan oleh tanaman secara alamiah.

Indole-3-Butyric Acid (IBA) merupakan salah satu jenis zat pengatur tumbuh (ZPT) sintesis yang mampu menghambat pertumbuhan lateral pada fase perkembangan tunas, serta merangsang inisiasi akar tanaman (Mehta et al., 2018). IBA dapat ditemukan sebagai bahan aktif pada berbagai produk rooting hormone hingga peningkatan tunas pada stek batang. Pada tanaman herba rosemary dan sage sesama famili Lamilaceae, perendaman dengan IBA mampu menunjukkan jumlah stek hidup terbaik (Lakehal et al., 2019). Namun, keberhasilan IBA dipengaruhi oleh berbagai faktor, yaitu konsentrasi, metode aplikasi, lama perendaman, suhu dan kelembapan, serta frekuensi aplikasi. Penelitian Karimi et al., (2014) menunjukkan bahwa stek batang Thymus saturoides dengan perlakuan konsentrasi IBA 500 ppm dan lama perendaman selama 2 menit menunjukkan grafik yang meningkat pada parameter akar seiring dengan penambahan konsentrasi IBA. Sedangkan Sabatino et al., (2014) menunjukkan bahwa lama perendaman berbagai tipe batang stek tanaman herba Teucrium fruticans pada larutan IBA $0,5 \%$ selama 5 atau 7 menit mampu memberikan persentase stek berakar dan jumlah akar terbaik. Keberhasilan perakaran akibat pemberian auksin eksogen akan berdampak pada parameter pertumbuhan yang lain, seperti jumlah tunas, jumlah daun, dan panjang tanaman.

Respon pertumbuhan tanaman terhadap pemberian IBA akan berbeda tergantung karakteristik morfologi dan fisiologi tanaman. Mekanisme masuknya auksin eksogen ke dalam jaringan tanaman yaitu melalui proses penyerapan air dan unsur hara, serta dipengaruhi oleh poses transpirasi yang terjadi di daun. Auksin eksogen masuk ke dalam jaringan tanaman melalui proses absorbsi dan dipengaruhi oleh permeabilitas membran sel tanaman (Alpriyan \& Karyawati, 2018; E. Amri et al., 2010). Proses difusi akan meningkatkan tekanan turgor dalam sel sehingga ZPT masuk ke dalam vakuola bersamaan dengan masuknya air yang selanjutnya dapat mengatur pertumbuhan sel (Ezekiel Amri, 2011; Hafizah, 2014). Meskipun auksin dapat diproduksi secara alami oleh tanaman itu sendiri, namun seringkali dalam jumlah yang sedikit sehingga diperlukan penambahan dari luar yang berasal dari ZPT alami maupun sintetik (Kim et al., 2021; Tustiyani, 2017). Beberapa jenis auksin sintetik yang umum dikenal yaitu IAA (Indole Acetic Acid), IBA (Indole-3-Butyric Acid), dan NAA (Naphtalene Acetic Acid) (Setiawan, 2017). Pada penelitian ini, aplikasi IBA dilakukan pada tanaman herba timi (Thymus vulgaris L.) dengan metode perendaman dan media perakaran berupa rockwool. Tujuan penelitian adalah untuk mengkaji pengaruh kombinasi perlakuan konsentrasi Indole-3-Butyric Acid (IBA) dengan lama perendaman terhadap pertumbuhan stek batang timi.

\section{BAHAN DAN METODE}

Penelitian dilaksanakan pada Januari - Maret 2020 di screen house PT. INDMIRA, Sleman, Yogyakarta dan Laboratorium Ekologi dan Produksi Tanaman Fakultas Peternakan dan Pertanian Universitas Diponegoro, Semarang. Bahan yang digunakan dalam penelitian yaitu batang timi, auksin IBA (Indole-3-Butyric Acid), rockwool dan media tanah. Alat yang digunakan yaitu polybag (22 cm x $20 \mathrm{~cm}$ ), mikropipet, gelas ukur, timbangan analitik, dan oven.

Penelitian dilaksanakan menggunakan rancangan acak lengkap pola faktorial $3 \times 4$ dengan 5 ulangan. Faktor pertama yaitu konsentrasi IBA (Indole-3-Butyric Acid), meliputi A0: 0 ppm, A1: 100 ppm, A2: 250 ppm, A3: 500 ppm. Faktor kedua yaitu lama perendaman, meliputi B1: 5 menit, B2: 10 menit, B3: 15 menit. Penelitian ini menggunakan 12 kombinasi perlakuan dengan 5 kali ulangan, sehingga terdapat 60 unit percobaan yang masing-masing terdiri dari 12 batang stek/unit percobaan.

Penelitian diawali dengan pembuatan larutan IBA sesuai perlakuan A dari larutan stok 1.000 ppm yang dibuat dengan cara melarutkan 1 gram IBA ke dalam 1 liter air. Konsentrasi IBA 100 ppm, 250 ppm, dan 500 ppm dibuat dengan cara mengencerkan $10 \mathrm{ml}, 25 \mathrm{ml}$, dan $50 \mathrm{ml}$ larutan IBA 1.000 ppm hingga volume mencapai $100 \mathrm{ml}$. Panjang bahan stek yang digunakan yaitu sekitar $9 \mathrm{~cm}$ yang diukur dari pucuk tanaman selain batang utama. Bahan tanam diperoleh dari tanaman utama berumur 2 tahun. Batang timi yang telah disiapkan direndam pada larutan IBA sesuai perlakuan konsentrasi. Waktu perendaman yaitu 5 menit, 10 menit, dan 15 menit dilakukan dengan bantuan stopwatch. Stek batang timi yang telah direndam sesuai perlakuan konsentrasi IBA dan lama perendaman langsung ditanam pada media rockwool berukuran $(2,5 \times 2,5) \mathrm{cm}$ dengan ketebalan $1,5 \mathrm{~cm}$ dengan masing-masing kotak ditanam 3 batang timi. Nampan plastik berisi rockwool yang telah ditanam stek batang timi disimpan dalam screen house. Selama masih di media rockwool, stek batang timi disiram setiap 2 hari agar tidak kering. Pemeliharaan lainnya yaitu sanitasi area tanam stek batang timi pada media rockwool untuk mencegah pertumbuhan jamur. Pindah tanam pada media tanah dilakukan pada minggu ke-3 setelah tanam atau ketika akar timi telah nampak di dasar rockwool. Komposisi media tanam yang digunakan yaitu tanah, pupuk kandang kambing, dan kompos dengan perbandingan 4:1:1 dalam polybag ukuran $22 \times 20 \mathrm{~cm}$. Jumlah stek batang yang ditanam tiap unit percobaan yaitu 12 batang yang diperoleh dari 4 kotak rockwool. Stek batang timi yang telah dipindah tanam pada media tanah diletakkan di dalam screen house. Pemeliharaan yang dilakukan meliputi penyiraman, sanitasi, dan penyulaman. Penyiraman dilakukan 2 kali sehari pagi dan sore. Penyulaman dilakukan 2 kali yaitu pada minggu ke-4 dan ke-5. Parameter pengamatan yang dilakukan di antaranya panjang tanaman, jumlah daun, persentase stek hidup, panjang akar, dan berat kering akar. Panjang tanaman, persentase stek hidup, dan berat kering akar diamati pada 8 MST sedangkan jumlah daun diamati setiap minggu mulai $3-8$ MST. Pengamatan jumlah daun, panjang tanaman, dan panjang akar dilakukan pada 4 tanaman sampel tiap unit percobaan (total ada 12 tanaman/unit percobaan), 
sedangkan pengamatan berat kering akar dilakukan pada total tanaman yang hidup di akhir masa penelitian (8 MST). Data yang diperoleh diolah menggunakan analisis ragam (Analysis of Variance = ANOVA) dan dilanjut dengan Uji Jarak Berganda Duncan (UJBD) pada taraf $5 \%$ apabila terdapat pengaruh perlakuan terhadap parameter yang diamati.

\section{HASIL DAN PEMBAHASAN \\ Panjang Tanaman}

Hasil analisis ragam menunjukkan bahwa perlakuan konsentrasi IBA berpengaruh nyata terhadap panjang tanaman dan perlakuan lama perendaman berpengaruh nyata terhadap panjang tanaman. Interaksi antara perlakuan konsentrasi IBA dengan lama perendaman menunjukkan hasil yang berbeda nyata terhadap panjang tanaman. Hasil uji jarak berganda Duncan perlakuan konsentrasi IBA dan lama perendaman terhadap panjang tanaman timi disajikan pada Tabel 1 memiliki kandungan $\mathrm{C}$ Organik $3,97 \%$ dan $\mathrm{N}$ Total 0,35\%.

Tabel 1. Panjang Tanaman Timi Pada Konsentrasi IBA dan Lama Perendaman (8 MST)

\begin{tabular}{ccccc}
\hline Konsentrasi & \multicolumn{2}{c}{ Lama Perendaman (menit) } & \multirow{2}{*}{ Rerata } \\
\cline { 2 - 4 } IBA $(\mathrm{ppm})$ & 5 & 10 & 15 & \\
\hline 0 & $16,55 \mathrm{bc}$ & $19,15 \mathrm{~b}$ & $12,55 \mathrm{def}$ & $16,08 \mathrm{a}$ \\
100 & $14,64 \mathrm{cde}$ & $15,90 \mathrm{bcd}$ & $10,53 \mathrm{f}$ & $13,69 \mathrm{~b}$ \\
250 & $12,72 \mathrm{def}$ & $22,26 \mathrm{a}$ & $12,40 \mathrm{ef}$ & $15,93 \mathrm{a}$ \\
500 & $14,35 \mathrm{cde}$ & $13,82 \mathrm{cdef}$ & $17,18 \mathrm{bc}$ & $15,12 \mathrm{ab}$ \\
\hline Rerata & $14,57 \mathrm{~b}$ & $17,88 \mathrm{a}$ & $13,17 \mathrm{~b}$ &
\end{tabular}

Keterangan: Notasi berbeda pada baris rerata, kolom rerata, atau matriks interaksi menunjukkan perbedaan nyata $(P<0,05)$

Tabel 1 menunjukkan terjadi penurunan hasil panjang tanaman seiring dengan penambahan lama perendaman pada konsentrasi IBA 0 ppm dan 100 ppm, bahwa pemberian IBA 100 ppm pada berbagai lama perendaman belum efektif meningkatkan panjang tanaman. Hal ini diduga karena stek batang timi mampu merespons IBA dengan baik sampai lama perendaman 10 menit, namun penambahan lama perendaman justru menyebabkan auksin menjadi berlebih. Pertumbuhan panjang tanaman yang optimum erat kaitannya dengan keberhasilan perakaran stek batang. Menurut Jan et al., (2015), IBA akan merangsang pembentukan akar adventif yang berfungsi menyerap mineral dan nutrisi dari tanah sehingga menjaga kelangsungan stek batang. Netopilova et al., (2021) menambahkan, pembentukkan primordial akar tergantung pada auksin endogen yang terdapat pada stek batang dan sinergitas dengan komponen lainnya.

Konsentrasi IBA 250 ppm meningkatkan panjang tanaman pada lama perendaman 10 menit, namun menurun apabila ditambah menjadi 15 menit (Tabel 1). IBA akan bekerja optimal apabila diberikan pada konsentrasi dan durasi waktu yang sesuai. Menurut Mehta et al., (2018), IBA merangsang pembelahan sel dan mengaktivasi tumbuhnya tunas apikal sehingga aplikasinya ke spesies tanaman tetentu dapat berdampak pada perpanjangan batang. Penambahan lama perendaman hingga 15 menit pada konsentrasi 250 ppm justru menghambat aktivasi tunas apikal. Aktivasi tunas apikal oleh auksin disebabkan karena terjadi perpanjangan sel. Mulyono, (2012) menjelaskan bahwa auksin mendorong perpanjangan sel dengan cara mempengaruhi metabolisme dinding sel yang berdampak pada perenggangan stuktural sel.

Konsentrasi IBA 500 ppm memberikan panjang tanaman yang tidak berbeda nyata seiring bertambahnya lama perendaman, dikarenakan pemberian auksin eksogen yang terlalu tinggi menyebabkan IBA tidak berpengaruh secara langsung terhadap panjang tanaman (Tabel 1). Hal ini sesuai dengan pendapat Arimarsetiowati \& Ardiyani, (2012) bahwa penggunaan konsentrasi yang tinggi harus dihindari karena dapat menyebabkan perlukaan pada tanaman. Pemberian IBA dengan konsentrasi tinggi dapat menghambat elongasi sel yang berdampak pada panjang tanaman. Menurut Kamila et al., (2020) kelebihan jumlah auksin pada jaringan tanaman akan ditranslokasikan ke bagian pangkal untuk pembentukkan kalus dan akar sehingga pertambahan tinggi terhambat.

Perendaman stek batang timi pada konsentrasi IBA 250 ppm selama 10 menit mampu meningkatkan panjang tanaman secara optimal dibandingkan kombinasi perlakuan yang lain. Keberadaan auksin pada jaringan tanaman sangat penting untuk mengatur proses fisiologi tanaman. Menurut Delcheh et al., (2014), auksin mengatur elongasi sel, perkembangan jaringan, serta meiosis dan embryogenesis sel tanaman. Faktor keberhasilan pemberian auksin eksogen salah satunya adalah kondisi lingkungan pada saat aplikasi auksin berlangsung. Menurut Suarmi et al., (2020), perendaman stek batang dalam larutan IBA harus dilakukan di tempat yang teduh dan lembab agar penyerapan IBA berjalan lancar.

\section{Jumlah Daun}

Hasil analisis ragam menunjukkan bahwa perlakuan konsentrasi IBA berpengaruh nyata terhadap jumlah daun dan perlakuan lama perendaman berpengaruh nyata terhadap jumlah daun. Interaksi antara perlakuan konsentrasi IBA dengan lama perendaman menunjukkan hasil yang berbeda nyata terhadap jumlah daun. Hasil uji jarak berganda Duncan perlakuan konsentrasi IBA dan lama perendaman terhadap jumlah daun timi disajikan pada Tabel 2.

Tabel 1. Jumlah Daun Timi Pada Konsentrasi IBA dan Lama Perendaman (8 MST)

\begin{tabular}{ccccc}
\hline Konsentrasi & \multicolumn{2}{c}{ Lama Perendaman (menit) } & \multirow{2}{*}{ Rerata } \\
\cline { 2 - 4 } IBA $(\mathrm{ppm})$ & 5 & 10 & 15 & \\
\hline 0 & $180 \mathrm{~b}$ & $152 \mathrm{bc}$ & $44 \mathrm{ef}$ & $126 \mathrm{a}$ \\
100 & $109 \mathrm{~cd}$ & $129 \mathrm{cde}$ & $32 \mathrm{f}$ & $90 \mathrm{~b}$ \\
250 & $76 \mathrm{de}$ & $265 \mathrm{a}$ & $58 \mathrm{ef}$ & $133 \mathrm{a}$ \\
500 & $141 \mathrm{bc}$ & $110 \mathrm{~cd}$ & $148 \mathrm{bc}$ & $133 \mathrm{a}$ \\
\hline Rerata & $127 \mathrm{~b}$ & $164 \mathrm{a}$ & $71 \mathrm{c}$ & \\
\hline
\end{tabular}

Keterangan: Notasi berbeda pada baris rerata, kolom rerata, atau matriks interaksi menunjukkan perbedaan nyata $(P<0,05)$.

Konsentrasi IBA 0 ppm dan 100 ppm menunjukkan respons yang sama, yaitu terjadi penurunan hasil jumlah daun seiring dengan penambahan lama perendaman (Tabel 2), dan penambahan lama perendaman pada konsentrasi IBA 100 ppm justru menghambat pembentukkan daun. Hal ini diduga karena terjadi pelukaan yang berlebihan pada permukaan batang sehingga mematikan bakal daun yang akan tumbuh. Durasi aplikasi auksin eksogen disesuaikan dengan metode yang digunakan, karakteristik bahan stek, dan bentuk auksin eksogen yang diberikan. Penelitian 
Aderounmu, (2019) menunjukkan bahwa IBA yang diberikan pada stek batang Vitellaria paradoxa dengan metode quick dip selama 5 detik memberikan hasil jumlah daun lebih tinggi dari tanaman kontrol. Kosakowska et al., (2021) berpendapat, keberhasilan stek untuk tumbuh dan berakar dipengaruhi oleh bahan stek, kedudukan bahan stek pada pohon induk, umur bahan stek, dan faktor eksternal (media tanam, suhu, dan kelembapan).

Konsentrasi IBA 500 ppm tidak menunjukkan perbedaan terhadap persentase stek hidup tanaman timi seiring dengan penambahan lama perendaman (Tabel 2). Hal ini diduga karena pengaruh konsentrasi auksin yang tinggi. Menurut Wiraswati \& Badami, (2018) bahwa konsentrasi IBA yang tinggi dapat merusak jaringan tanaman. Peningkatan jumlah daun akibat pemberian IBA merupakan respons tidak langsung tanaman akibat keberhasilan perakaran dan ketersediaan cadangan makanan dalam pembentukan tunas daun. Menurut pendapat Brondani et al., (2012) bahwa batang stek yang berasal dari tanaman induk yang telah masak berpengaruh terhadap keberhasilan stek batang karena berhubungan dengan cadangan makanan tanaman.

Terjadi kenaikan jumlah daun pada konsentrasi IBA $250 \mathrm{ppm}$ seiring dengan penambahan lama perendaman, namun penambahan hingga 15 menit justru menurunkan jumlah daun (Tabel 2). Hal ini menunjukkan bahwa semakin lama direndam, maka respons tanaman semakin buruk. Hal ini sesuai dengan pendapat Mulyani \& Ismail, (2015) bahwa kandungan IBA secara tepat akan meningkatkan aktivitas pembelahan dan perpanjangan sel yang berdampak pada peningkatan jumlah daun. Pemberian IBA dengan konsentrasi IBA $250 \mathrm{ppm}$ selama 10 menit mampu memberikan hasil jumlah daun tertinggi dibandingkan dengan perlakuan yang lain, karena auksin eksogen berhasil masuk ke jaringan tanaman dan merangsang pertumbuhan. Mekanisme masuknya IBA ke jaringan tanaman agar dapat merangsang munculnya daun terjadi melalui proses penyerapan air oleh tanaman. Menurut Saha et al., (2021) bahwa proses difusi akan meningkatkan tekanan turgor dalam sel sehingga ZPT masuk ke dalam vakuola bersamaan dengan masuknya air yang selanjutnya dapat mengatur pertumbuhan sel dan primordial daun.

\section{Persentase Stek Hidup}

Hasil analisis ragam menunjukkan bahwa perlakuan konsentrasi IBA berpengaruh nyata terhadap persentase stek hidup dan perlakuan lama perendaman berpengaruh nyata terhadap persentase stek hidup. Interaksi antara perlakuan konsentrasi IBA dengan lama perendaman menunjukkan hasil yang berbeda nyata terhadap persentase stek hidup. Hasil uji jarak berganda Duncan perlakuan konsentrasi IBA dan lama perendaman terhadap persentase stek hidup timi disajikan pada Tabel 3. Terjadi penurunan persentase stek hidup seiring dengan penambahan lama perendaman pada konsentrasi IBA 0 ppm dan 100 ppm (Tabel 3). Hal ini menunjukkan bahwa pemberian IBA dengan konsentrasi 100 ppm belum mampu meningkatkan persentase stek hidup timi, diduga karena ketersediaan auksin endogen telah cukup sehinga tidak membutuhkan auksin eksogen. Hal ini sesuai dengan pendapat Nguyen et al., (2020) yang menyatakan bahwa keberhasilan auksin eksogen berhubungan dengan keseimbangan auksin endogen dan kadar karbohidrat (cadangan makanan) yang ada pada bahan stek. Persentase stek hidup menunjukkan tingkat keberhasilan stek batang timi dengan perlakuan IBA sebagai auksin eksogen. Auksin pada jaringan tanaman berperan dalam merangsang terbentuknya akar sehingga mampu menyerap air dan unsur hara. Yunus et al., (2016) menambahkan, pemberian IBA dengan konsentrasi tinggi pada kondisi hormon endogen yang telah tersedia justru akan mengambat kemunculan akar.

Tabel 2. Persentase Stek Hidup Timi Pada Konsentrasi IBA dan Lama Perendaman (8 MST)

\begin{tabular}{ccccc}
\hline Konsentrasi & \multicolumn{2}{c}{ Lama Perendaman (menit) } & \multirow{2}{*}{ Rerata } \\
\cline { 2 - 4 } IBA $(\mathrm{ppm})$ & 5 & 10 & 15 & \\
\hline 0 & $85,00 \mathrm{a}$ & $71,67 \mathrm{abc}$ & $51,67 \mathrm{bc}$ & $51,67 \mathrm{c}$ \\
100 & $93,33 \mathrm{a}$ & $78,33 \mathrm{a}$ & $48,33 \mathrm{c}$ & $48,33 \mathrm{bc}$ \\
250 & $73,33 \mathrm{ab}$ & $98,33 \mathrm{a}$ & $78,33 \mathrm{a}$ & $78,33 \mathrm{ab}$ \\
500 & $90,00 \mathrm{a}$ & $86,67 \mathrm{ab}$ & $86,67 \mathrm{a}$ & $86,67 \mathrm{a}$ \\
\hline Rerata & $85,42 \mathrm{a}$ & $83,75 \mathrm{a}$ & $66,25 \mathrm{~b}$ & \\
\hline
\end{tabular}

Keterangan: Notasi berbeda pada baris rerata, kolom rerata, atau matriks interaksi menunjukkan perbedaan nyata $(P<0,05)$.

Perlakuan konsentrasi IBA 250 ppm dan 500 ppm memberikan persentase stek hidup yang tidak berbeda nyata seiring dengan penambahan lama perendaman (Tabel 3), diduga karena konsentrasi auksin endogen dan cadangan makanan yang terkandung dalam batang stek telah cukup digunakan untuk merangsang perakaran. Hal ini sesuai dengan pendapat Hossain et al., (2004) bahwa auksin berperan dalam mengaktivasi hidrolisis polisakarida menjadi lebih sederhana yang diperlukan sebagai energi dan penyediaan cadangan makanan bagi jaringan meristematik dan primordia akar. Tanaman secara alami akan memanfaatkan cadangan makanan untuk pembentukkan akar yang dapat dibantu oleh IBA sebagai auksin eksogen. Faktor konsentrasi IBA yang terlalu tinggi menyebabkan batang menjadi busuk dan menghambat perakaran. Menurut Djamhari, (2012) bahwa hormon tumbuhan (fitohormon) bekerja aktif dalam jumlah sedikit yang ditransformasikan ke seluruh bagian tanaman sehingga berpengaruh terhadap pertumbuhan dan proses fisiologi tanaman.

Pemberian IBA pada berbagai konsentrasi dan lama perendaman belum mampu meningkatkan persentase stek hidup. Hal ini ditunjukkan dengan perlakuan IBA memberikan hasil stek hidup yang sama dengan tanpa diberi IBA (Tabel 3). Hasil tersebut serupa dengan penelitian Sevik \& Guney, (2013) bahwa hormon IAA, IBA, dan NAA yang diaplikasikan pada stek batang lemon balm (Melissa officinalis L.) tidak berbeda nyata dengan kontrol terhadap parameter persentase stek berakar. Hal ini diduga karena kandungan auksin endogen yang tinggi pada stek batang timi, sehingga tidak membutuhkan auksin eksogen. Penelitian Apriliani et al., (2015) menunjukkan bahwa pemberian auksin tidak berpengaruh terhadap persentase berakar stek pucuk bayur (Pterosperinum javanicum Jungh.), diduga karena auksin endogen yang terdapat pada tanaman tersebut sudah cukup sehingga pemberian auksin tidak berpengaruh. Cadangan makanan yang cukup pada batang stek timi menyebabkan pertumbuhan tunas dapat terjadi secara alami tanpa bantuan auksin eksogen. Wulandari Fitria et al., (2017) menambahkan, pada fase awal pertumbuhan, cadangan makanan 
berupa karbohidrat, $\mathrm{C}$, dan $\mathrm{N}$ pada stek batang merupakan sumber energi yang sangat mempengaruhi pertumbuhan tunas.

\section{Panjang Akar}

Hasil analisis ragam menunjukkan bahwa perlakuan konsentrasi IBA berpengaruh nyata terhadap panjang akar dan perlakuan lama perendaman berpengaruh nyata terhadap panjang akar. Interaksi antara perlakuan konsentrasi IBA dengan lama perendaman menunjukkan hasil yang berbeda nyata terhadap panjang akar. Hasil uji jarak berganda Duncan perlakuan konsentrasi IBA dan lama perendaman terhadap panjang akar timi disajikan pada Tabel 4 .

Tabel 3. Panjang Akar Tanaman Timi pada Konsentrasi IBA dan Lama Perendaman (8 MST)

\begin{tabular}{ccccc}
\hline Konsentrasi & \multicolumn{2}{c}{ Lama Perendaman (menit) } & \multirow{2}{*}{ Rerata } \\
\cline { 2 - 4 } IBA $(\mathrm{ppm})$ & 5 & 10 & 15 & \\
\hline 0 & $8,15 \mathrm{c}$ & $11,28 \mathrm{~b}$ & $4,89 \mathrm{e}$ & $8,10 \mathrm{a}$ \\
100 & $8,91 \mathrm{c}$ & $7,95 \mathrm{c}$ & $3,85 \mathrm{e}$ & $6,91 \mathrm{~b}$ \\
250 & $5,72 \mathrm{de}$ & $14,11 \mathrm{a}$ & $6,98 \mathrm{~cd}$ & $8,94 \mathrm{a}$ \\
500 & $9,07 \mathrm{c}$ & $7,64 \mathrm{~cd}$ & $8,20 \mathrm{c}$ & $8,31 \mathrm{a}$ \\
\hline Rerata & $7,96 \mathrm{~b}$ & $10,25 \mathrm{a}$ & $5,98 \mathrm{c}$ & \\
\hline
\end{tabular}

Notasi berbeda pada baris rerata, kolom rerata, atau matriks interaksi menunjukkan perbedaan nyata $(P<0,05)$.

Konsentrasi IBA 0 ppm dan 250 ppm meningkatkan hasil panjang akar pada lama perendaman 10 menit, namun menurun pada lama perendaman 15 menit (Tabel 4). Hasil tersebut menunjukkan bahwa penambahan lama perendaman pada konsentrasi IBA yang tinggi akan menghambat perakaran stek batang timi. Hal ini sesuai dengan penelitian Okafor et al., (2020; Shalini Kaushik \& Neeraj Shukla, (2020) terhadap stek rosemary yang menunjukkan bahwa semakin lama waktu perendaaman stek batang dalam larutan IBA, maka semakin rendah nilai panjang akar. Repons perakaran yang ditunjukkan oleh tiap jenis tanaman tidak selalu sama karena adanya perbedaan karakteristik batang stek. Menurut Karimi et al., (2014) bahwa tingkat sensitifitas jaringan dalam merespons auksin eksogen berpengaruh terhadap keberhasilan perakaran sehingga respons perakaran akan berbedabeda.

Hasil yang berbeda tidak nyata seiring penambahan lama perendaman terjadi pada perlakuan IBA 500 ppm (Tabel 4) diduga karena pengaruh auksin yang tinggi menyebabkan peran auksin terhadap perakaran tidak optimal. Pemberian auksin yang berlebihan dapat menghambat perakaran, diduga karena adanya etilen yang dipicu oleh auksin (Arlianti et al., 2014; Pacholczak \& Nowakowska, 2020). Fahly et al., (2017) menambahkan bahwa konsentrasi IBA yang terlalu tinggi akan mengganggu keseimbangan hormon yang ada pada bahan tanam sehingga dapat menyebabkan kerusakan pada bagian batang yang terluka dan mencegah tumbuhnya tunas dan akar.

Pemberian IBA dengan konsentrasi 250 ppm dan lama perendaman 10 menit memberikan hasil panjang akar terbaik dibandingkan kombinasi perlakuan yang lainnya (Tabel 4). Akar yang panjang menyebabkan tanaman lebih leluasa menyerap air dan unsur hara yang dibutuhkan untuk menunjang pertumbuhan tanaman. Penelitian Paradiković et al., (2013) yang menguji respons IBA pada jenis tanaman herba yang lain menunjukkan bahwa aplikasi IBA mampu meningkatkan faktor pertumbuhan dan perkembangan, di antaranya tinggi tanaman, panjang akar, berat segar dan berat kering akar stek batang rosemary dan sage. Karimi et al., (2014) menambahkan, setiap spesies tanaman memiliki spesifikasi tersendiri terhadap rasio sitokinin dan auksin endogen, serta tingkat sensitifitas jaringan dalam merespons auksin eksogen sehingga respons perakaran akan berbeda-beda.

\section{Berat Kering Akar}

Hasil analisis ragam menunjukkan bahwa perlakuan konsentrasi IBA tidak berpengaruh nyata terhadap berat kering akar dan perlakuan lama perendaman berpengaruh nyata terhadap berat kering akar. Interaksi antara perlakuan konsentrasi IBA dengan lama perendaman menunjukkan hasil yang berbeda nyata terhadap berat kering akar. Hasil uji jarak berganda Duncan perlakuan konsentrasi IBA dan lama perendaman terhadap berat kering akar timi disajikan pada Tabel 5.

Tabel 4. Berat Kering Akar Tanaman Timi pada Konsentrasi IBA dan Lama Perendaman (8 MST)

\begin{tabular}{ccrrr}
\hline Konsentrasi & \multicolumn{2}{c}{ Lama Perendaman (menit) } & \multirow{2}{*}{ Rerata } \\
\cline { 2 - 4 } IBA $(\mathrm{ppm})$ & 5 & 10 & 15 & \\
\hline 0 & $27,28 \mathrm{c}$ & $39,47 \mathrm{~b}$ & $14,57 \mathrm{de}$ & 27,11 \\
100 & $26,77 \mathrm{c}$ & $37,44 \mathrm{~b}$ & $12,72 \mathrm{e}$ & 25,64 \\
250 & $20,51 \mathrm{~cd}$ & $51,16 \mathrm{a}$ & $13,95 \mathrm{de}$ & 28,54 \\
500 & $35,93 \mathrm{~b}$ & $23,25 \mathrm{c}$ & $14,70 \mathrm{de}$ & 24,48 \\
\hline Rerata & $27,62 \mathrm{~b}$ & $37,83 \mathrm{a}$ & $13,99 \mathrm{c}$ & \\
\hline
\end{tabular}

Keterangan: Notasi berbeda pada baris rerata, kolom rerata, atau matriks interaksi menunjukkan perbedaan nyata $(P<0,05)$.

Perlakuan konsentrasi IBA 0 ppm, 100, ppm, dan 250 ppm menunjukkan hasil berat kering akar yang meningkat seiring dengan penambahan lama perendaman menjadi 10 menit, namun menurun secara signifikan pada lama perendaman 15 menit (Tabel 5). Hal ini terjadi karena karakteristik batang timi yang lunak akan rusak apabila direndam terlalu lama. Karakteristik batang berhubungan dengan proses masuknya air ke dalam jaringan tanaman guna merangsang pembentukkan akar adventif. Menurut Lakehal et al., (2019) bahwa auksin eksogen masuk ke dalam jaringan tanaman melalui proses absorbsi dan dipengaruhi oleh permeabilitas membran sel. Terbentuknya akar adventif pada perbanyakan stek batang lebih banyak dipengaruhi oleh cadangan makanan yang terdapat di batang stek, karena belum terbentuk akar untuk menyerap nutrisi dari tanah. Diduga, cadangan makanan pada bahan stek telah cukup sehingga aplikasi IBA tidak membutuhkan waktu yang lama. Semakin besar ukuran stek, maka semakin besar pasokan cadangan makanan (karbohidrat) yang dimiliki untuk membentuk organ vegetatif baru (Kaushik \& Shukla, 2020).

Konsentrasi IBA 500 ppm memberikan hasil yang semakin rendah seiring pertambahan lama perendaman (Tabel 5), diduga karena faktor auksin eksogen tinggi menghambat perakaran timi. Hal ini sesuai dengan pendapat Zaman et al., (2020) bahwa pemberian auksin yang berlebihan dapat menghambat perakaran karena adanya etilen yang dipicu oleh auksin. Hasil penelitian ini berbeda dengan penelitian Denaxa et al., (2021) yang menghasilkan perakaran stek Thymus saturoides terbaik seiring dengan peningkatan konsentrasi IBA hingga 500 ppm selama 2 menit. Respon jaringan 
tanaman terhadap jenis auksin maupun level konsentrasi akan berbeda pada setiap tanaman (Arlianti et al., 2014; De Almeida et al., 2017; Mishra et al., 2020).

Pemberian IBA dengan konsentrasi 250 ppm dan lama perendaman 10 menit mampu meningkatkan berat kering akar tanaman timi secara optimal dibandingkan dengan perlakuan yang lainnya karena peran auksin dalam merangsang perakaran (Tabel 5). Beberapa proses yang diatur oleh IBA di antaranya merangsang pembelahan sel, menginduksi perakaran, perpanjangan batang dan koleoptil, dominansi apikal, dan diferensiasi jaringan pengangkut (Kumar et al., 2019). Faktor lain yang mempengaruhi perakaran stek tanaman yaitu bahan stek yang digunakan. Bagian batang yang digunakan, umur tanaman induk, dan perlakuan IBA berpengaruh terhadap persentase stek berakar yang berhubungan dengan keseimbangan auksin endogen dan kadar karbohidrat (cadangan makanan) pada bahan stek (Arumugam et al., 2020; Kosakowska et al., 2021; Martínez et al., 2020; Muthulakshmi et al., 2020). Pada taraf Perlakuan B0, B1, B2 B3 dan B4 tidak berpengaruh nyata terhadap peningkatan $\mathrm{N}$ total pada tanah. Hal ini dikarenakan perlunya waktu penelitian yang lebih lama untuk dilakukannya pembibitan tanaman kelapa sawit Tustiyani, (2017) membuktikan bahwa biochar mampu meretensi $\mathrm{N}$ dan $\mathrm{P}$ sehingga tidak mudah hanyut terbawa air dan akan lebih tersedia bagi tanaman. Penggunaan biochar dalam tanah ultisol di Amerika Serikat bisa meningkatkan $\mathrm{pH}$ tanah, C-organik tanah, $\mathrm{Mn}$ dan Ca serta mengurangi S dan Zn (Hussain et al., 2020; Lakehal et al., 2019; Rao et al., 2020).

\section{KESIMPULAN}

Perlakuan konsentrasi IBA 250 ppm dan lama perendaman 10 menit memberikan hasil terbaik pada parameter panjang tanaman, jumlah daun, panjang akar, dan berat kering akar. Perendaman dalam air (tanpa IBA) selama 5 menit mampu memberikan hasil jumlah tunas dan persentase stek hidup (85\%) terbaik sehingga pemberian IBA tidak diperlukan.

\section{DAFTAR PUSTAKA}

Aderounmu, A. F. (2019). Effects of stock age, hormone types and concentrations on rooting and early growth of Vitellaria paradoxa C. F. Gaertn. Stem Cuttings. Journal of Advances in Biology \& Biotechnology, 22(2), https://doi.org/10.9734/jabb/2019/v22i230109

Alpriyan, D., \& Karyawati, A. S. (2018). Pengaruh konsentrasi dan lama perendaman hormon auksin pada bibit tebu (Saccharum officinarum L.) teknik bud chip. Jurnal Produksi Tanaman, 6(7), 1354-1362.

Amri, E., Lyaruu, H. V. M., Nyomora, A. S., \& Kanyeka, Z. L. (2010). Vegetative propagation of african blackwood (Dalbergia melanoxylon Guill. \& Perr.): effects of age of donor plant, IBA treatment and cutting position on rooting ability of stem cuttings. New Forests, 39(2), 183-194. https://doi.org/10.1007/s11056-009-9163-6

Amri, Ezekiel. (2011). The effect of auxins (IBA, NAA) on vegetative propagation of medicinal plant. Tanzania Journal of Natural and Applied Sciences (TaJONAS), 2(2), 359-366.

Apriliani, A., Noli, Z. aneloi, \& Suwiren. (2015). Pemberian beberapa jenis dan konsentrasi auksin untuk menginduksi perakaran pada stek pucuk bayur (Pterospermum javanicum Jungh.) dalam upaya perbanyakan tanaman revegetasi. Jurnal Biologi Universitas Andalas (J. Bio. UA.), 4(3), 178-187.

Arimarsetiowati, R., \& Ardiyani, F. (2012). Pengaruh penambahan auxin terhadap pertunasan dan perakaran kopi arabika perbanyakan somatic embryogenesis. Pelita Perkebunan (a Coffee and Cocoa Research Journal), 28(2), 82-90. https://doi.org/10.22302/iccri.jur.pelitaperkebunan.v2 $8 \mathrm{i} 2.201$

Arlianti, T., Syahid, S. F., Kristina, N. N., \& Rostiana, O. (2014). Pengaruh auksin IAA, IBA, dan NAA terhadap induksi perakaran tanaman stevia (Stevia rebaudiana) secara in vitro. Buletin Penelitian Tanaman Rempah Dan Obat, 24(2), 57-62. https://doi.org/10.21082/bullittro.v24n2.2013.

Arumugam, G., Sinniah, U. R., Swamy, M. K., \& Lynch, P. T. (2020). Micropropagation and essential oil characterization of Plectranthus amboinicus (Lour.) sprengel, an aromatic medicinal plant. In Vitro Cellular and Developmental Biology - Plant, 56(4), 491-503. https://doi.org/10.1007/s11627-020-100561

Brondani, G. E., Baccarin, F. J. B., de Wit Ondas, H. W., Stape, J. L., Gonçalves, A. N., \& de Almeida, M. (2012). Low temperature, IBA concentrations and optimal time for adventitious rooting of Eucalyptus benthamii mini-cuttings. Journal of Forestry Research, 23(4), 583-592. https://doi.org/10.1007/s11676-012-0298-5

Dauqan, E. M. A., \& Abdullah, A. (2017). Medicinal and functional values of thyme (Thymus vulgaris L.) Herb. Journal of Applied Biology \& Biotechnology, 5(02), 17-22. https://doi.org/10.7324/jabb.2017.50203

De Almeida, M. R., Aumond, M., Da Costa, C. T., Schwambach, J., Ruedell, C. M., Correa, L. R., \& Fett-Neto, A. G. (2017). Environmental control of adventitious rooting in Eucalyptus and Populus cuttings. Trees - Structure and Function, 31(5), 13771390. https://doi.org/10.1007/s00468-017-1550-6

Delcheh, K. S., Kashefi, B., \& Mohammadhassan, R. (2014). A review optimization of tissue culture medium medicinal plant: Thyme. International Journal of Farming and Allied Sciences, 3(9), 10151019.

Denaxa, N. K., Vemmos, S. N., \& Roussos, P. A. (2021). Shoot girdling improves rooting performance of kalamata olive cuttings by upregulating carbohydrates, polyamines and phenolic compounds. Agriculture (Switzerland), 11(1), 1-16. https://doi.org/10.3390/agriculture11010071

Djamhari, S. (2012). Memecah Dormansi Rimpang Temulawak (Curcuma xanthorrhiza Roxb) menggunakan larutan atonik dan stimulasi perakaran dengan aplikasi auksin. Jurnal Sains dan Teknologi Indonesia, 12(1), 66-70. https://doi.org/10.29122/jsti.v12i1.852

Elhaak, M., \& Gad, D. (2015). Propagation principles in using Indole-3-Butyric Acid for rooting rosemary stem cuttings. Journal of Horticulture, 02(01). https://doi.org/10.4172/2376-0354.1000121 
Fahly, M., Barus, A., \& Haryati. (2017). Pengaruh beberapa komposisi media tanam dan konsentrasi IBA (Indole Butiric Acid) terhadap pertumbuhan setek basal daun mahkota tanaman nenas (Ananas comosus L. Merr.). Jurnal Agroteknologi FP USU, 5(4), 854-859.

Hafizah, N. (2014). Pertumbuhan stek mawar (Rosa damascena Mill.) pada waktu perendaman dalam larutan urine sapi. Ziraa'ah, 39(3), 129-135.

Hossain, M. A., Islam, M. A., \& Hossain, M. M. (2004). Rooting ability of cuttings of Swietenia macrophylla King and Dillenia indica $L$. as influenced by exogenous hormone. International Journal of Agriculture and Biology, 6(April 2015), 560-564.

Hussain, K., Qadri, R., Akram, M. T., Nisar, N., Iqbal, A., Yang, Y., Khan, M. M., Imran-Ul-Haq, Khan, R. I., \& lqbal, M. A. (2020). Clonal propagation of olive (Olea europeae) through semi- hardwood cuttings using IBA under shaded polyethylene tunnels (SPTS). Fresenius Environmental Bulletin, 29(9 A), 81318137.

Jan, I., Iqbal, A., Bhutta, M., \& Ahmad, N. (2015). Effect of various concentra tions of indole butyric acid (IBA) on olive cuttings. mitt Eilungen Klosterneuburg, 65: 49-55.

Javed, H., Erum, S., Tabassum, S., \& Ameen, F. (2013). An overview on medicinal importance of Thymus vulgaris. Journal of Asian Scientific Research, 3(10), 974-982.

Juárez-Rosete, C., Aguilar-Castillo, J., \& RodriguezMendoza, M. (2014). Fertilizer source in biomass production and quality of essential oils of thyme (Thymus vulgaris L.). European Journal of Medicinal Plants, 4(7), https://doi.org/10.9734/ejmp/2014/9169

Kamila, P. K., Das, P. K., Mohapatra, P. K., \& Panda, P. C. (2020). Effect of auxins on rooting of stem cuttings in Hypericum gaitii. Journal of Herbs, Spices and Medicinal Plants, 26(4), 423-434. https://doi.org/10.1080/10496475.2020.1749207

Karimi, M., Berrichi, A., \& Boukroute, A. (2014). Study of vegetative propagation by cuttings of Thymus satureioides. Journal of Materials and Environmental Science, 5(4), 1320-1325.

Kaushik, S., \& Shukla, N. (2020). Effect of IBA and NAA and their combination on the shooting of stem cuttings of african marigold (Tagetes erecta L.) cV. pusa narangi gainda. International Journal of Chemical Studies, 8(3), 1800-1802. https://doi.org/10.22271/chemi.2020.v8.i3y.9462

Kim, S. H., Kim, J. H., Oh, H. J., Kim, S. Y., \& Suh, G. U. (2021). Vegetative propagation of Veronica dahurica and Veronica pusanensis by stem cuttings with auxins. Rhizosphere, 17, 100315. https://doi.org/10.1016/j.rhisph.2021.100315

Kosakowska, O., Węglarz, Z., \& Bączek, K. (2021). The Effect of open field and foil tunnel on yield and quality of the common thyme (Thymus vulgaris L.), in organic farming. Agronomy, 11(2), 197. https://doi.org/10.3390/agronomy11020197

Kumar, S., Malik, A., Yadav, R., \& Yadav, G. (2019). Role of different rooting media and auxins for rooting in floricultural crops: A review. International Journal of Chemical Studies, 7(2), 1778-1783.

Lakehal, A., Chaabouni, S., Cavel, E., Le Hir, R., Ranjan, A., Raneshan, Z., Novák, O., Păcurar, D. I., Perrone, I., Jobert, F., Gutierrez, L., Bakò, L., \& Bellini, C. (2019). A molecular framework for the control of adventitious rooting by TIR1/AFB2-Aux/IAADependent auxin signaling in Arabidopsis. Molecular Plant, 12(11), 1499-1514. https://doi.org/10.1016/j.molp.2019.09.001

Martínez, M. T., Vieitez, F. J., Solla, A., Tapias, R., Ramírez-Martín, N., \& Corredoira, E. (2020). Vegetative propagation of Phytophthora cinnamomitolerant holm oak genotypes by axillary budding and somatic embryogenesis. Forests, 11(8). https://doi.org/10.3390/F11080841

Mehta, S., Singh, K., Singh Harsana, A., \& Mehta, C. S. (2018). Effect of IBA concentration and time of planting on rooting in pomegranate (Punica granatum) cuttings. Journal of Medicinal Plants Studies JMPS, 25053(61), 250-253. http://www.plantsjournal.com/archives/2018/vol6issu e1/PartD/6-1-30-120.pdf

Mishra, P., Roggen, A., Ljung, K., \& Albani, M. C. (2020). Natural variation in adventitious rooting in the alpine perennial arabis alpina. Plants, 9(2), 1-9. https://doi.org/10.3390/plants9020184

Mulyani, C., \& Ismail, J. (2015). Pengaruh konsentrasi dan lama perendaman rootone $f$ terhadap pertumbuhan stek pucuk jambu air (Syzygium semaragense) Pada Media Oasis. Agrosamudra, 2(2), 1-9.

Mulyono, D. (2012). Pengaruh zat pengatur tumbuh auksin: indole butiric acid (IBA) dan sitokinin: benzil amino purine (BAP) dan kinetin dalam elongasi pertunasan gaharu (Aquilaria beccariana). Jurnal Sains dan Teknologi Indonesia, 12(1), 1-7. https://doi.org/10.29122/jsti.v12i1.842

Muthulakshmi, V., Vijayam, C. V., Bachpai, V. K. W., Sivakumar, V., Muthulakshmi, E., Shanmugavel, S., Muneera Parveen, A. B., Yasodha, R., Rajasugunasekar, D., Nagarajan, B., Mayavel, A., \& Ghosh Dasgupta, M. (2020). Genetic control of adventitious rooting traits in bi-parental pedigree of Eucalyptus tereticornis $\times$ E. camaldulensis. New Forests, https://doi.org/10.1007/s11056-020-09810-5

Netopilova, M., Houdkova, M., Urbanova, K., Rondevaldova, J., \& Kokoska, L. (2021). Validation of qualitative broth volatilization checkerboard method for testing of essential oils: Dual-column gc-fid/ms analysis and in vitro combinatory antimicrobial effect of origanum vulgare and thymus vulgaris against staphylococcus aureus in liquid and vapor phases. Plants, 10(2), 1-23. https://doi.org/10.3390/plants10020393

Nguyen, T. Q., Nguyen, B. H., Thi, D. H. T., Thi, O. D., Nguyen, Q. N., \& Vo, C. C. (2020). Rooted cuttings by IBA (indole butyric acid) and NAA (Naphthalene acetic acid) in black pepper (piper nigrum) - A case study in Vietnam. International Journal of Chemical Studies, 8(3), 1880-1885. https://doi.org/10.22271/chemi.2020.v8.i3z.9480 
Okafor, C. U., Njoku, E. U., Ike, F. C., \& Onyekwuluje, C. C. (2020). Indole-3-Butyric acid induces plant regeneration from stem cuttings of three medicinal plants. Nigerian Journal of Biotechnology, 37(1), 109-121. https://doi.org/10.4314/njb.v37i1.12

Pacholczak, A., \& Nowakowska, K. (2020). The effect of biostimulators and indole-3-butyric acid on rooting of stem cuttings of two ground cover roses. Acta Agrobotanica, 73(1), 1-9. https://doi.org/10.5586/aa.7314

Paradiković, N., Zeljković, S., Tkalec, M., Vinković, T., Dervić, I., \& Marić, M. (2013). Influence of rooting powder on propagation of sage (Salvia officinalis L.) and rosemary (Rosmarinus officinalis L.) with green cuttings. Poljoprivreda, 19(2), 10-15.

Rahardjo, R., Darwati, I., \& Nurhayati, H. (2020). Pengaruh pemupukan terhadap pertumbuhan, produksi, dan mutu tanaman timi (Thymus vulgaris L.). Jurnal Penelitian Tanaman Industri, 20(4), 195. https://doi.org/10.21082/jlittri.v20n4.2014.195-202

Rao, G. S. K., Bisati, I. A., Sharma, A., Kosser, S., Bhat, S. A., \& Bisati, A. (2020). Effect of IBA concentration and cultivars on number of leaves, leaf area and chlorophyll content of leaf in Pomegranate (Punica granatum L.) cuttings under tempera conditions of Kashmir. Journal of Pharmacognosy and Phytochemistry, SP6, 86-90. http://www.phytojournal.com

Sabatino, L., D'Anna, F., \& lapichino, G. (2014). Cutting type and IBA treatment duration affect Teucrium fruticans adventitious root quality. Notulae Botanicae Horti Agrobotanici Cluj-Napoca, 42(2), 478-481. https://doi.org/10.1583/nbha4229611

Saha, R., Ginwal, H. S., Chandra, G., \& Barthwal, S. (2021). A comparative study on grey relational analysis and C5.0 classification algorithm on adventitious rhizogenesis of Eucalyptus. Trees Structure and Function, 35(1), 43-52. https://doi.org/10.1007/s00468-020-02008-4

Salehi, B., Mishra, A. P., Shukla, I., Sharifi-Rad, M., Contreras, M. del M., Segura-Carretero, A., Fathi, H., Nasrabadi, N. N., Kobarfard, F., \& Sharifi-Rad, J. (2018). Thymol, thyme, and other plant sources: Health and potential uses. Phytotherapy Research, 32(9), 1688-1706. https://doi.org/10.1002/ptr.6109

Setiawan, E. (2017). Efektivitas pemberian IAA, IBA, NAA, dan root-up pada pembibitan kesemek. Jurnal Hortikultura Indonesia, 8(2), 97. https://doi.org/10.29244/jhi.8.2.97-103
Sevik, H., \& Guney, K. (2013). Effects of IAA, IBA, NAA, and GA3 on rooting and morphological features of melissa officinalis L. stem cuttings. The Scientific World Journal, 2013(2001). https://doi.org/10.1155/2013/909507

Shalini Kaushik, \& Neeraj Shukla. (2020). A review on effect of IBA and NAA and their combination on the rooting of stem cuttings of different ornamental crops. Journal of Pharmacognosy and Phytochemistry, 9(3), 1881-1885.

http://www.phytojournal.com/archives/?year=2020\&v ol=9\&issue $=3 \&$ part $=A E \&$ Articleld $=11588$

Suarmi, F., Sukerta, I., \& Ananda, K. (2020). Penggunaan zat perangsang tumbuh indole butyric acid (IBA) pada stek kembang kertas (Bougainvillea spectabilis ). Agrimeta, 10(19), 38-41.

Tustiyani, I. (2017). Pertumbuhan stek kopi the effect of various natural plant growth regulator on growth cuttings of coffee. Jurnal Pertanian, 8, 46-50. file:///F:/Jurnal Kopi/565-1984-2-PB.pdf

Wiraswati, S. F., \& Badami, K. (2018). Pengaruh pemberian IBA dan asal stek terhadap pertumbuhan vegetatif kumis kucing. Agrovigor: Jurnal Agroekoteknologi, 11(2), 65-70. https://doi.org/10.21107/agrovigor.v11i2.4392

Wulandari Fitria, Murti Astiningrum, \& Tujiyanta. (2017). Pengaruh jumlah daun dan macam media tanam pada pertumbuhan stek jeruk nipis (Citrus aurantifolia Swingle). Jurnal IImu Pertanian Tropika Dan Subtropika, 2(2), 48-51. https://translate.google.com/translate?hl=en\&sl=id\& $\mathrm{u}=\mathrm{http}$ ://jurnal.untidar.ac.id/index.php/vigor/article/vie $w / 487 / 394 \&$ prev $=$ search

Yunus, A., Rahayu, M., Samanhudi, Pujiasmanto, B., \& Riswanda, H. (2016). Respon kunir putih (Kaempferia rotunda) terhadap pemberian IBA dan BAP pada kultur in vitro. Agrosains : Jurnal Penelitian Agronomi, 18(June), 44-49.

Zaman, M. A. K., Azzeme, A. M., Ramle, I. K., Normanshah, N., Ramli, S. N., Shaharuddin, N. A., Ahmad, S., \& Abdullah, S. N. A. (2020). Induction, multiplication, and evaluation of antioxidant activity of polyalthia bullata callus, a woody medicinal plant. Plants, 9(12), 1-21. https://doi.org/10.3390/plants9121772 